\title{
Advances in lunar science from the Clementine mission: A decadal perspective
}

\author{
Mark Robinson* and Miriam Riner \\ Center for Planetary Sciences, Northwestern University, 1850 Campus Drive, Evanston, IL 60208, USA. \\ *e-mail: robinson@earth.northwestern.edu
}

\begin{abstract}
The Clementine spacecraft orbited the Moon and acquired science data for 10 weeks in the Spring of 1994. During this time it collected global 11-band multispectral images and near global altimetry. Select areas of the Moon were imaged at $25 \mathrm{~m} /$ pixel in visible light and $60 \mathrm{~m} /$ pixel in thermal wavelengths. From these datasets a new paradigm for the evolution of the lunar crust emerged. The Moon is no longer viewed as a two-terrane planet, the Apollo samples were found not to represent the lunar crust as a whole, and the complexity of lunar crustal stratigraphy was further revealed. More than ten years later the Clementine datasets continue to significantly advance lunar science and will continue to do so as new measurements are returned from planned missions such as Chandrayaan, SELENE, and Lunar Reconnaissance Orbiter. This paper highlights the scientific research conducted over the last decade using Clementine data and summarizes the influence of Clementine on our understanding of the Moon.
\end{abstract}

\section{Introduction}

The Apollo lunar missions returned a wealth of data in the form of samples, in situ measurements, orbital remote sensing, and observations by highly trained astronauts that served to characterize the geology of six locations in great detail. Soviet robotic rovers and sample return missions also contributed substantially to our understanding of the Moon. Advances in lunar geology since the Apollo era were stymied by the lack of a global digital dataset that could be used for extrapolation of the results from returned sample analyses to the whole Moon. Before Clementine it was not known whether materials in the Apollo collection provided a representative sample of all the major geologic units on the Moon. This issue was critical since the Apollo samples predominantly shaped our views of the formation and evolution of the Moon, yet all these samples came from a small region centered on the lunar nearside. Until the return of the global Clementine multispectral and altimetry measurements the issue remained open.
Lunar compositional mapping by color difference and spectroscopic methods has been known since the 1960s. However, only the nearside of the Moon can be seen from Earth, individual Apollo sample stations are not resolvable from Earth, and telescopic spectral observations are limited to several kilometer resolution. Thus, only modest progress was possible towards obtaining high resolution mineralogical and compositional maps from Earth-based methods.

Earth-based telescopic observations and Galileo lunar flybys in 1990 and 1992 showed the potential of digital multispectral imaging in advancing our understanding of the Moon and underscored the scientific potential of an orbital multispectral campaign. The Clementine spacecraft, which orbited the Moon for 10 weeks in 1994 (McEwen and Robinson 1997; Nozette et al 1994) and transmitted over 35 Gigabytes (compressed) of science data, made significant progress towards fulfilling this potential. The ultra-violet visible (UVVIS) and near-infrared (NIR) cameras provided the first global digital multispectral (11 filters, 415 to

Keywords. Clementine; remote sensing; multispectral imaging; lunar surface mineralogy.

J. Earth Syst. Sci. 114, No. 6, December 2005, pp. 669-686

(C) Printed in India. 
$2792 \mathrm{~nm}$ ) measurements for the Moon at a resolution of $\sim 100-500 \mathrm{~m} /$ pixel (Lucey et al 1994; Nozette et al 1994; Pieters et al 1994; Shoemaker et al 1994). A laser-ranger (LIDAR) collected ranging measurements from approximately $70^{\circ} \mathrm{S}$ to $70^{\circ} \mathrm{N}$ providing the first near global topographic model of the Moon (30 km spatial resolution) (Smith et al 1997; Zuber et al 1994). The long wavelength infrared (LWIR) camera returned $8.3 \mathrm{~km}$ swaths of 8-9 micron temperature measurements nested within each $44 \mathrm{~km}$ wide UVVIS mapping orbit, covering approximately $20 \%$ of the Moon (Lawson et al 2000). The highresolution (HIRES) camera acquired multispectral (25-50 m/pixel effective) images over targets of interest, and complete monochrome coverage of the polar regions (Robinson et al 2003). The Clementine Charged Particle Telescope (CPT) provided flux measurements of energetic particles (Baker 1997). While not strictly science instruments, the star tracker cameras (ST) returned measurements of the near-lunar environment and inter-planetary space. A rich scientific return has resulted from analyses of these data by a host of investigators, reshaping the scientific community's view of the Moon and spurring new exploration efforts (figure 1). Since 1994 hundreds of Clementine based abstracts (i.e., 626 Lunar and Planetary Science Conference abstracts through 2005) and over 130 peer-reviewed papers ( 7 in 1994, 1 in 1995, 7 in 1996, 15 in 1997, 10 in 1998, 18 in 1999, 21 in 2000,14 in 2001, 18 in 2002, 21 in 2003, 5 in 2004, and 4 in the first half of 2005) have appeared in the scientific literature. The intent of this review is to highlight the contributions of these works and summarize the overall picture of our current understanding of the Moon as influenced by Clementine. References to previous work in fields reviewed here can be found in the referenced Clementine based papers and overviews such as the Lunar Sourcebook (Heiken et al 1991), and The Geologic History of the Moon (Wilhelms 1987).

\section{Compositional and mineralogical mapping}

Exploiting $\mathrm{FeO}$ induced spectral absorptions in major lunar crustal minerals, Lucey and colleagues transformed the Clementine Spectral Reflectance (CSR) measurements to $\mathrm{FeO}$ abundance (Blewett et al 1997a; Lucey et al 1998a; Lucey et al 1998b; Lucey et al 2000a; Gillis et al 2004), and in the process disentangled maturity effects (Lucey et al 2000b; Lucey et al 1995). An alternative technique for quantifying the maturity of lunar highlands soils at the Apollo 16 site was developed by Fischer and Pieters (1996), but proved to be

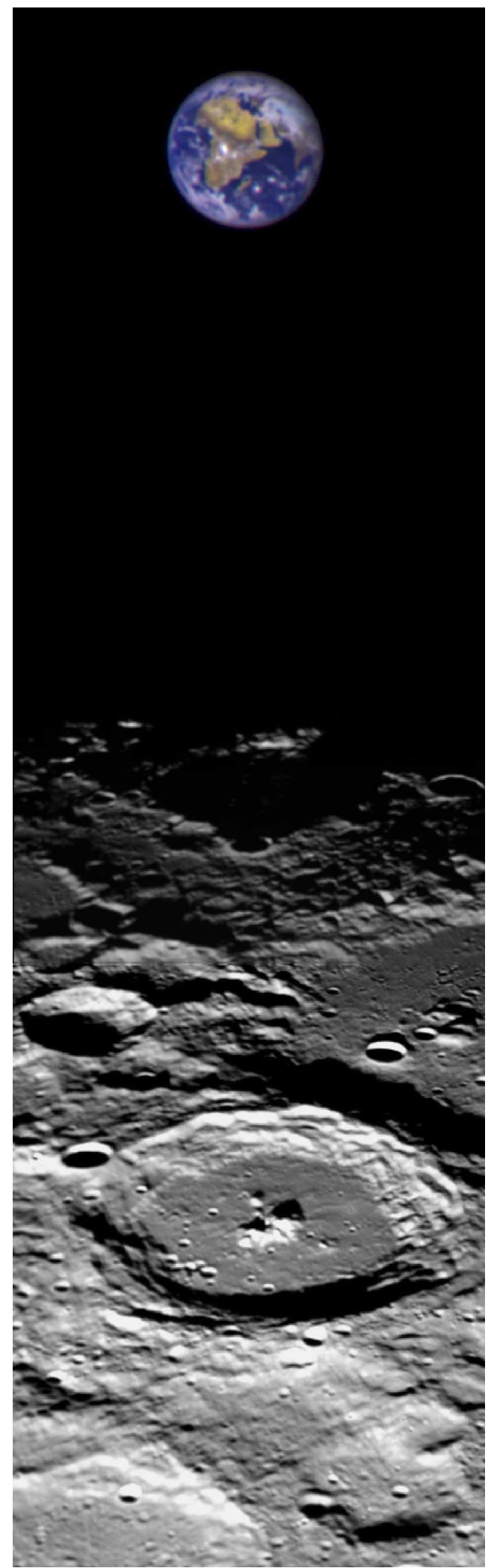

Figure 1. The Clementine spacecraft was the first scientific platform to orbit the Moon since the Apollo era. A hallmark of the mission was the ability of mission operations to respond to real-time requests for non-standard observations such as this UVVIS camera view of the Earth over the lunar north pole. The position of the Earth relative to the Moon was shifted downward about a factor of two to fit on this journal page (Clementine UVVIS images from orbit 102). 
too limited for generalized use. Utilizing a method similar to the $\mathrm{FeO}$ inversion, $\mathrm{TiO}_{2}$ abundances were also estimated (Blewett et al 1997a; Lucey et al 1998a, 2000a; Gillis and Jolliff 2003). The FeO, maturity, and $\mathrm{TiO}_{2}$ methods are simple and each relies on analysis of only two UVVIS wavelengths, $750 \mathrm{~nm}$ and $950 \mathrm{~nm}$ ( $\mathrm{FeO}$ and maturity) or $750 \mathrm{~nm}$ and $415 \mathrm{~nm}\left(\mathrm{TiO}_{2}\right)$. The global $\mathrm{FeO}$ map showed that the lunar highlands crust typically contains 3-4 wt\% FeO, consistent with the hypothesis that the crust mostly formed through flotation from a magma ocean. The global FeO map also suggests that the lunar bulk (crust plus mantle) silicate composition may be significantly different than the Earth's mantle: if true, models of lunar formation that require the Earth and Moon to have similar silicate compositions would be discounted (Lucey et al 1995).

An alternative $\mathrm{FeO}$ abundance algorithm was developed exploiting the UVVIS and NIR images to more fully define the 1-micron iron absorption feature and the overall continuum slope (Le Mouelic et al 2000, 2002). FeO abundance estimates from this approach generally agree with the FeO map from Lucey and coworkers (1998a). Differences are attributed to the effect of local slopes (this method is less sensitive to local topography than Lucey et al (1998a) because it uses only band ratios) or variations in olivine or titanium content.

Clark and McFadden (2000) compared iron abundances derived from CSR and Apollo gammaray (AGR) measurements and attributed abundance differences to ferrous iron in olivine not detected in the CSR. However, it was later shown (Lawrence et al 2002) that the discrepancy was due to uncorrected neutron density variations in the AGR data, and not shortcomings in the CSR FeO method.

Early CSR work investigating the dependence of the spectral slope at visible wavelengths and titanium abundance at the Apollo landing sites indicated a non-linear correlation between titanium abundance and 415/750 nm ratio (Blewett et al 1997a; Lucey et al 1998a, 2000a). Careful selection of CSR pixels for Apollo and Luna sample stations directly linked the data to returned soil analyses. That allowed Blewett et al (1997a) to apply a sample based calibration for the titanium values. Variations in $\mathrm{TiO}_{2}$ concentration are remarkably good unit discriminators in the mare and also provide proxies for understanding compositional variations within the lunar mantle, thus accurate remote sensing abundances are valuable indicators of lunar geologic evolution. Titanium abundances derived from Lunar Prospector data are in some cases not in good agreement with CSR results and this problem is discussed in section 11, Lunar Prospector and Clementine. Recent work by Gillis and Jolliff (2003) identified two distinct trends in the $\mathrm{TiO}_{2}$ spectral parameter plot and derived two regression parameters to better fit the sample data resulting in improved fits (Gillis et al 2004). Campbell and coworkers (1997) and Ghent and others (2005) compared CSR $\mathrm{TiO}_{2}$ maps to $70 \mathrm{~cm}$ radar returns and found positive correlation with titanium content. The relation between lunar opaques, titanium, and spectral reflectance is an ongoing research activity.

The UVVIS CSR data allow derivation of mineralogy maps for most of the Moon (figures 2, 3) (Tompkins and Pieters 1999; Pieters et al 2001; Staid and Pieters 2001; Lucey 2004). Plagioclase feldspar and clinopyroxene abundances were found to correlate with $\mathrm{FeO}$ content (inversely and directly, respectively), leading to the inference that plagioclase is the major carrier of aluminum and clinopyroxene is the major source of iron. Clinopyroxene is found in major abundances in all mare, and surprisingly large abundances of orthopyroxene were found in some mare (i.e., Frigoris, Orientale, Australe). Orthopyroxene in general is not correlated with other mineral abundances or $\mathrm{FeO}$. Apollo samples indicated that orthopyroxene should be common in all highland crustal materials, however the CSR mineral mapping showed orthopyroxene to be absent in large regions of farside highlands. The dominant mafic mineral found in the farside highlands is olivine (albeit at a few per cent) with pyroxene being absent or nearly so, raising the possibility that the olivine was originally included in the flotation crust (Lucey 2004).

A lack of prelaunch calibration data, large uncertainties in gain and offset values, and a large temperature dependant dark signal slowed the interpretation of the Clementine NIR data set. McEwen et al (1994) and Le Mouelic et al (1999a,

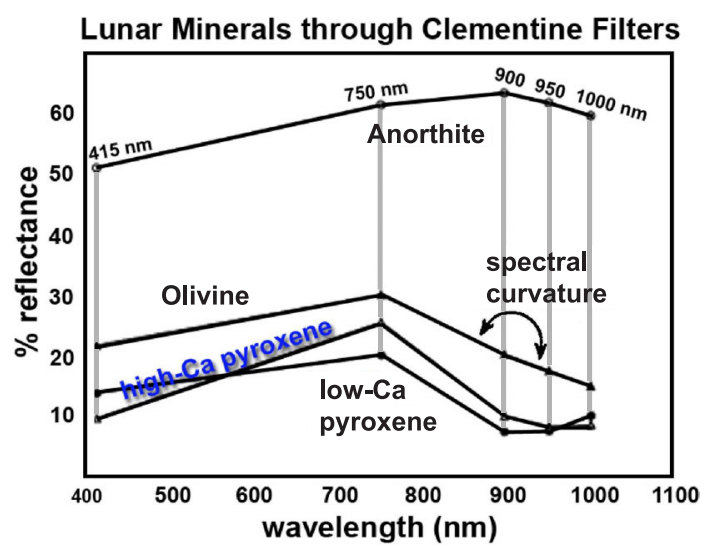

Figure 2. Schematic diagram illustrating general principles used by Tompkins and Pieters (1999) to determine mineralogic abundance from the Clementine UVVIS bandpasses (see text for details). 


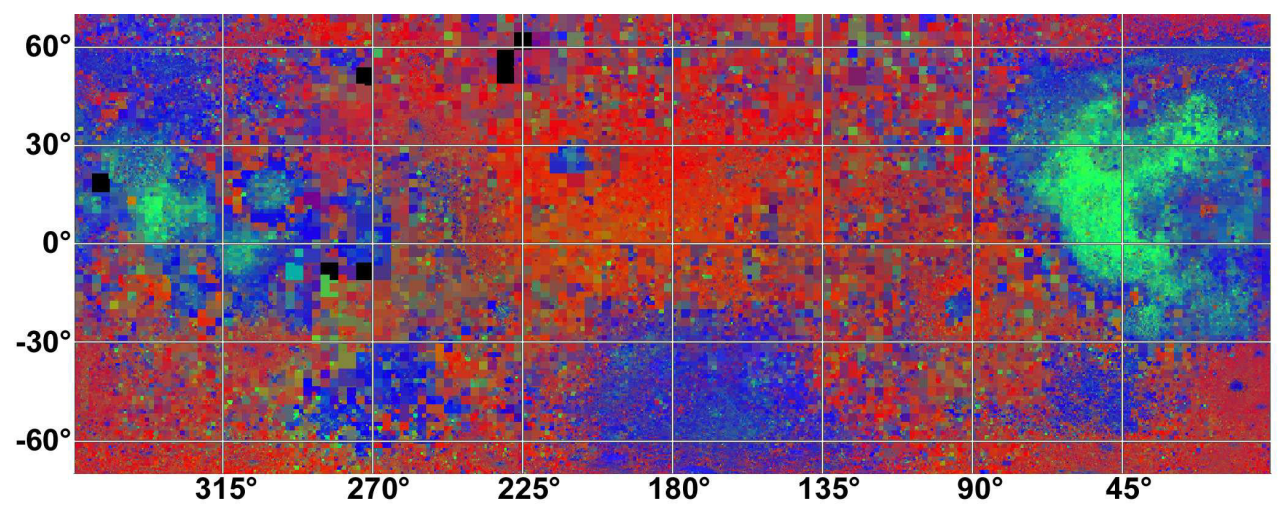

Figure 3. Generalized mineral map of the Moon; red indicates relative anorthite abundance, green represents olivine abundance, and blue shows total pyroxene abundance (clinopyroxene plus orthopyroxene). The map is centered on the farside of the Moon $\left(180^{\circ} \mathrm{W}\right.$ longitude) highlighting the large-scale compositional unit associated with the South Pole-Aitken basin (approximately centered at $45^{\circ} \mathrm{S}$ and $160^{\circ} \mathrm{W}$ ). Note the lack of olivine (green) in the SPA, hinting that the SPA impact event did not excavate mantle material. Note also the large region of olivine basalts (green) in western Oceanus Procellarum $\left(15^{\circ} \mathrm{N}, 55^{\circ} \mathrm{W}\right)$. The black regions indicate no compositional estimates available. The data are from Lucey (2004).

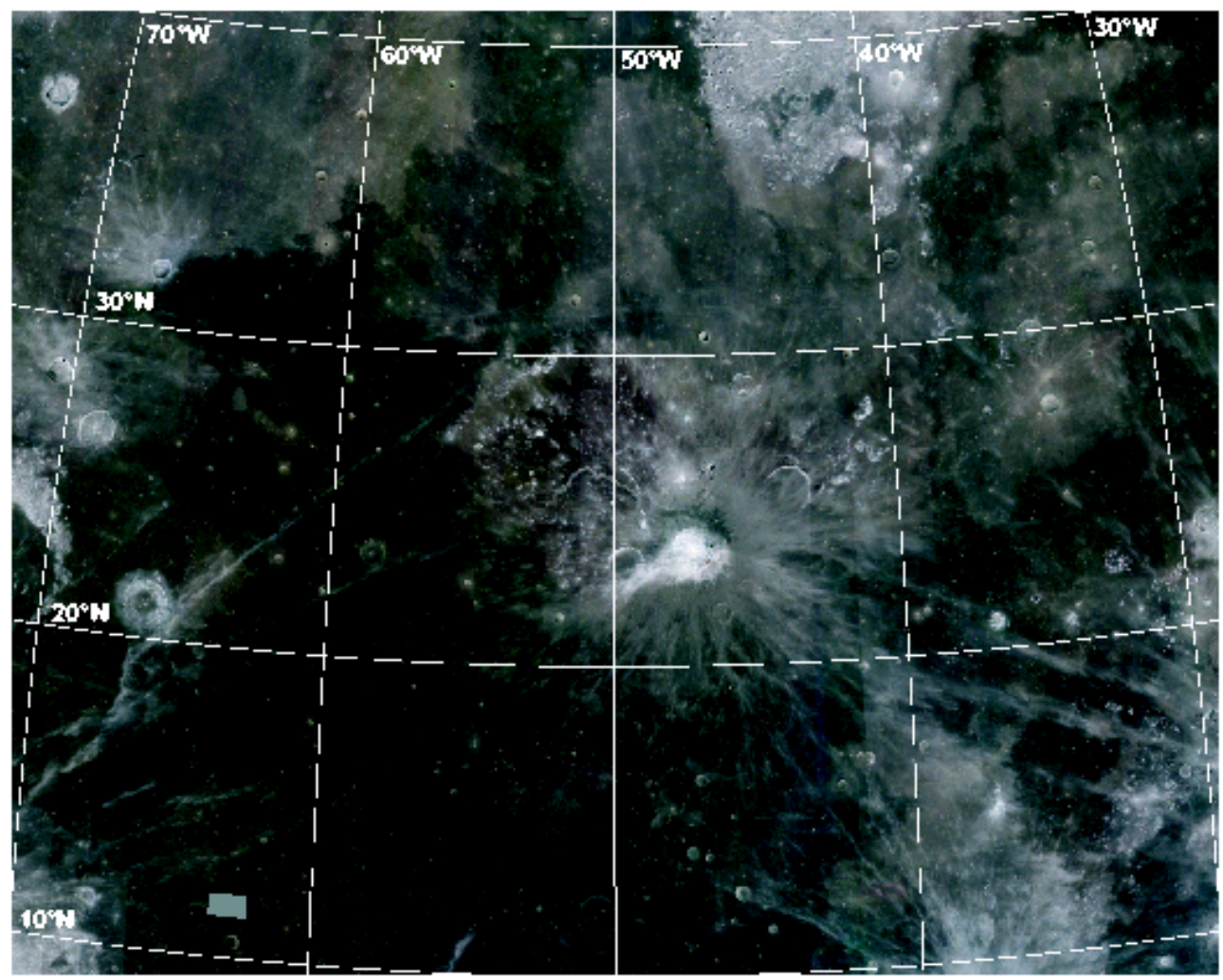

Figure 4. Mosaic of the Aristarchus Plateau from Clementine NIR images (red $=1500 \mathrm{~nm}$, green $=1250 \mathrm{~nm}$, blue $=1100 \mathrm{~nm}$ ). Newly available NIR fully calibrated mosaics (Eliason et al 2003) will result in better discrimination of color units and more confident interpretations of mineralogy and composition. The Copernican aged Aristarchus crater $\left(23.9^{\circ} \mathrm{N}, 47.4^{\circ} \mathrm{W}\right)$ excavated feldspathic material from beneath Oceanus Procellarum mare basalts revealing an unusual olivine rich deposit (McEwen et al 1994; Le Mouelic et al 1999a, 1999b).

1999b) employed empirical calibration approaches with telescopic spectra and in-flight dark frames to obtain mineralogical information for limited sets of NIR images covering small regions (figure 4). These empirically calibrated NIR data were used to determine the distribution of olivine in craters
Aristarchus (McEwen et al 1994) and Copernicus providing clues of magmatic processes in the lunar mantle and crust (Le Mouelic et al 1999a; Le Mouelic and Langevin 2001; Daydou et al 2003).

One of the most significant findings from the CSR data is the characterization of the 
compositional anomaly occupying the interior of the $2500 \mathrm{~km}$ diameter South Pole-Aitken (SPA) basin (Pieters et al 1997; Lucey et al 1998b, 1995; Pieters et al 2001; Chevrel et al 2002b; Lucey 2004). The floor of the basin has an $\mathrm{FeO}$ content intermediate $(10-12 \mathrm{wt} \%)$ between that of mare and highlands (Lucey et al 1998b, 1995) and is rich in pyroxene (both clino- and orthopyroxene) and generally lacking in olivine (Tompkins and Pieters 1999; Lucey 2004). Early work examining the SPA had considered the possibility that an unusual crustal composition is exposed, or that lower crustal (Pieters et al 2001, 1997), and perhaps upper mantle material was exposed near the center of the basin (Lucey et al 1998b; Pieters et al 2001). Olivine is only present locally and in small abundances indicating that no mantle material is exposed (Pieters et al 1997; Lucey 2004), or the mantle in this portion of the Moon has an unusual composition (Lucey 2004). Gravity and topography based models of the lunar crust predict the SPA impact did not excavate through the relatively thick pre-existing crust, consistent with the current $\mathrm{FeO}$ and mineral abundance estimates of the basin floor (Wieczorek and Phillips 1998). FeO mapping, mineral abundance distributions, and gravity models are converging on the hypothesis that the mafic anomaly in the SPA floor is due to exposure of lower crustal materials relatively rich in pyroxene, emplaced as part of the original flotation crust or as subsequent intrusions (Wieczorek and Zuber 2001; Lucey 2004).

The UVVIS instrument acquired data at resolutions typically ranging from 100 to 200 meters per pixel (angular resolution at a single pixel) allowing detailed study of small scale features, particularly useful in providing context to returned samples (Blewett et al 1997a; Tompkins and Pieters 1999; Robinson and Jolliff 2002; Zellner et al 2002). Jolliff (1999) examined the relationship between returned soil geochemistry and pixel scale CSR values to elucidate the range of compositional heterogeneities found in the Apollo 17 landing site region (mare and highlands). This study found evidence supporting the idea that layers of mafic rich impact melt are exposed in the surrounding massifs and that topographic facets can adversely affect accuracy of $\mathrm{FeO}$ and $\mathrm{TiO}_{2}$ values (Lucey et al 1998a; Jolliff 1999). These small highland heterogeneities were more accurately characterized by combining high resolution Apollo era topography with the CSR photometric correction (Robinson and Jolliff 2002). It was found that the topographic effects are significant, yielding errors as high as $5 \mathrm{wt} \% \mathrm{FeO}$ and $4 \mathrm{wt} \% \mathrm{TiO}_{2}$ (absolute) on $30^{\circ}$ slopes. The magnitude of the correction varies for Sun-facing versus anti-Sun slopes, with greater changes on anti-Sun slopes (Robinson and Jolliff 2002).

\section{Mare}

Many studies have exploited CSR ratios and other derived spectral parameters $\left(\mathrm{FeO}, \mathrm{TiO}_{2}\right.$, mineral abundances) to map distinct flow units both between and within nearly all mare on the Moon (Pieters and Tompkins 1999; Tompkins and Pieters 1999; Yingst and Head 1999; Giguere et al 2000; Staid and Pieters 2000; Heather and Dunkin 2002b; Hiesinger et al 2003; Kodama and Yamaguchi 2003). Surprisingly, a broad portion of the western nearside mare basalts have an unusually wide 1-micron band (Staid and Pieters 2001), interpreted to represent basalts with high olivine content, up to $50 \mathrm{wt} \%$ olivine (figure 3) (Lucey 2004). No equivalent rock-type is represented in the lunar sample collection. Also, detailed investigation of $\mathrm{TiO}_{2}$ abundances within and between mare deposits reveal a continuous distribution peaking at $2-4 \mathrm{wt} \%$ rather than a bimodal distribution indicated by Apollo samples; this continuous distribution is proposed to be consistent with formation from cumulates in a magma ocean (Giguere et al 2000).

A class of dark halo craters has long been hypothesized to indicate excavation of more mafic material beneath feldspathic material. CSR data provide the spatial resolution to identify and characterize such deposits. The extent of ancient mare buried by subsequent emplacement of feldspathic highlands material can be estimated by the identification of dark halo craters and approximations of their depths of excavation (Staid et al 1996). In the reverse case the thickness of mare deposits can be accurately estimated from the smallest crater that excavates underlying feldspathic basement material. The latter method indicates mare units in northwestern Tranquillitatis basin which are significantly thicker than previous estimates (Staid et al 1996). Conversely, the overall thickness of Humorum mare deposits is estimated near the low end of previous estimates. The resulting volume estimates are two times lower than those generally assumed, important not only for magma eruption estimates but also for modeling loads on the crust (Budney and Lucey 1998). The same method was also applied to constrain mare thicknesses in southern Oceanus Procellarum (Heather and Dunkin 2002b) and to investigate the thickness and compositional evolution of flows within the full depth of Mare Serenitatis and Tranquillitatis (Rajmon and Spudis 2004). Hawke et al (2002) detailed the occurrence of a dark halo deposit in the lunar southern highlands at the crater Buck B (6 $\mathrm{km}$ diameter). They proposed that a small mare puddle was covered with a thin layer of feldspathic ejecta and was subsequently excavated by a later small impact. Alternatively the mafic ejecta may 
represent a near-surface mafic intrusion that was brought to the surface during the formation of Buck B. This unusual deposit is far from any mare deposits and further demonstrates the compositional complexity of the highlands.

Mapping the distribution of mare and highland units in the Smythii-Marginis region using CSR data, showed the existence of an extensive mare deposit thinly covered by highland material (Yingst and Head 1998; Gillis and Spudis 2000). Additionally mare occurrences were associated with regions of locally thinned crust (Yingst and Head 1998) and the total volume of exposed and buried mare materials were shown to be insufficient to explain the local mascon anomaly, demanding uplift of denser mantle materials during local basin formation (Gillis and Spudis 2000). Geospatial analysis of small mare ponds in the Orientale and South Pole-Aitken basins led to the inference that single eruptive events are large, on the scale of terrestrial flood basalt deposits, and emanate from deep (subcrustal) reservoirs (Yingst and Head 1997).

\section{Dark mantle deposits}

CSR maps facilitated the identification and characterization of local and regional lunar dark mantling deposits (Weitz et al 1998; Head et al 2002; Gaddis et al 2000, 2003; Giguere et al 2003). Such deposits are generally thought to be the result of explosive volcanism (pyroclastic), but details of their composition and emplacement mechanisms are not known. Weitz et al (1998) estimated the ratio of glass to crystalline material in major regional dark mantle deposits using variations in the $415 / 750 \mathrm{~nm}$ and $750 / 950 \mathrm{~nm}$ ratios tied to spectral measurements of returned pyroclastic materials. This study also examined the significance of the glass to crystalline ratio in terms of plume structure and emplacement mechanisms. Further examination of variations in CSR parameters in both local and regional deposits led to the conclusion that the deposits are more complex in terms of composition and levels of crystallinity than previously thought (Gaddis et al 2000, 2003).

\section{Lunar swirls}

Analyses of CSR data indicate that the enigmatic lunar swirl deposits in the Smythii-Marginis region (Gillis and Spudis 2000) and Reiner Gamma Formation (Pinet et al 2000) are relatively immature with a composition indistinguishable from that of their surroundings. These observations narrow the nature of the swirl deposits to represent either a recent scouring event (possibly cometary) or magnetic shielding of solar wind inhibiting space weathering mechanisms (Gillis and Spudis 2000; Pinet et al 2000). Photometric analyses of Clementine images of Reiner Gamma also indicate that the surface is anomalously smooth and young relative to average mare, perhaps supporting a recent impact/scouring hypothesis (Kreslavsky et al 2000; Kreslavsky and Shkuratov 2003).

Clementine and telescopic NIR reflectance spectra of an area of unusually high albedo in the Descartes highlands, also known to be a magnetic anomaly, indicates the mineralogy of the albedo feature that is similar to nearby materials. However, optical maturity images show the material to be fresher than the nearby portion of the Descartes highlands and that reddening, normally a consequence of space weathering, has not occurred within the high albedo unit. These findings are consistent with the hypothesis that a region of high magnetics is protecting the affected area from the solar wind, and that solar wind is a requirement for normal space weathering (Blewett et al 2005).

\section{Anorthosite}

Hawke and coworkers (2003b) utilized Earthbased telescopic spectra, Galileo image data and Clementine image data to map the distribution and interpret the significance of occurrences of anorthosite across the entire Moon. They found that a global anorthosite layer composes the upper portion of the crust, underlain almost everywhere by a more mafic layer. Numerous regional studies have detailed this multi-layered crust (Pieters et al 1994; Bussey and Spudis 1997, 2000; Blewett and Hawke 2001; Heather and Dunkin 2002a, 2003). Hawke and coworkers (2003b) noted that outcrops of anorthosite, while not common, do occur within the Procellarum region and no underlying mafic layer has yet been identified, consistent with the hypothesis that Procellarum is not an impact feature. Blewett and Hawke (2001) characterized the Hadley-Apennine region through an integrated analysis of CSR and Lunar Prospector composition estimates and found that the Apenninus material and Alpes Formation are geochemically distinct, thus underscoring the evolving idea that the highlands crust is compositionally complex both vertically and laterally.

\section{Highland mare mixing}

Workers used CSR based spectral unmixing techniques to investigate the relative importance of mixing between highland and mare units due to 
impact processes (Mustard et al 1998; Li and Mustard 2000, 2003). The symmetrical distribution of mare materials in the highlands (and highlands material in the mare) along highland/mare contacts indicates that the dominant process is lateral mixing rather than vertical excavation $(\mathrm{Li}$ and Mustard 2000). Further analysis of highlands contamination of three eastern mare led to the conclusion that a few large impacts may account for the majority of highland-mare mixing (Li and Mustard 2003). It is possible that latitudinally uncorrected scattered light in the UVVIS sensor (Robinson et al 2003) and/or uncertainties in photometric corrections influenced these mixing results.

\section{Cratering}

Craddock and Howard (2000) applied photoclinometric techniques to derive topographic profiles of 1-3 km diameter craters in farside mare. A diffusion model combined with the topographic profiles led the authors to propose a general rate of erosion from micrometeorite bombardment of $0.2 \mathrm{~mm} / 10^{6} \mathrm{yr}$, a rate five times slower than generally accepted. They propose that farside basalts are all of Imbrian age and that the erosion rate since this period has slowed gradually with time.

To test the hypothesis that small comets $\left(10^{7}\right.$ to $10^{8}$ grams) frequently impact the Earth, Grier and McEwen (1997) compared Apollo era photography with Clementine $750 \mathrm{~nm}$ images to determine if any new ( $\geq 50 \mathrm{~m}$ diameter) impact craters were detectable. Sampling a statistically significant portion of the lunar surface they found no new craters and thus showed the small comet impact rate to be fallacious.

McEwen and coworkers (1997) mapped the global distribution of rayed craters from the lowphase angle Clementine $750 \mathrm{~nm}$ basemap and presented evidence that the cratering rate in the past $300 \mathrm{Ma}$ may have increased by up to a factor of two. A later count identified rayed craters using the optical maturity (OMAT) parameter of Lucey et al (2000b) resulting in fewer identifications of mature rayed craters (Grier et al 2001). This improved count weakened the earlier argument for an increase in the recent cratering rate. Another count of rayed craters from the Clementine $750 \mathrm{~nm}$ basemap by Morota and Furumoto (2003) resulted in a proposed asymmetry of Copernican aged craters between the nearside and the farside suggesting to the authors that most recent impacts on the Moon were from near-Earth asteroids and not comets. Nagumo and Nakamura (2001) examined the shape of craters $<4 \mathrm{~km}$ diameter and proposed that ellipticities greater than 1.2 indicate secondary craters. In a detailed study of lunar rays Hawke and coworkers (2004) concluded that the determination of a Copernican age crater should be based on the relative maturity of ray materials quantified by the OMAT parameter (Lucey et al 2000b) rather than the mere presence of ray, thus avoiding the confusion of compositional versus maturity rays.

\section{Non-mare volcanism}

The high resolution of the Clementine data allow detailed spectral mapping of suspected non-mare volcanic regions and suggest a more diverse volcanic history than previously established (Chevrel et al 1999; Weitz and Head 1999; Heather et al 2003). Hawke and coworkers (2003a) showed that the composition of Hansteen Alpha, a suspected non-mare volcanic highland feature (FeO abundance $5-9 \%$ and $\mathrm{TiO}_{2}$ values $<1 \%$ ) is incompatible with mare $\left(\mathrm{FeO}>16 \%\right.$ and $\left.\mathrm{TiO}_{2} 4-8 \%\right)$ and highland ( $\mathrm{FeO} 10-14 \%$ and $\mathrm{TiO}_{2} 1-3 \%$ ) compositions for that region. Lawrence and coworkers (2005) used Clementine spectral data with Lunar Prospector gamma-ray data to model the Th abundances in the Hansteen Alpha region. High Th abundance $(25 \mu \mathrm{g} / \mathrm{g})$ indicates that Hansteen Alpha may be composed of rhyolite. Blewett and Hawke (2001) showed that the Apennine Bench Formation (ABF) has $\mathrm{Fe}$, Ti, and $\mathrm{Th}$ composition equal to Apollo 15 KREEP basalt samples previously proposed to represent the $\mathrm{ABF}$ further strengthening previous arguments that the formation represents a large-scale non-mare volcanic unit.

\section{Lunar space environment}

Solar wind-implanted ${ }^{3} \mathrm{He}$ has been considered a possible lunar resource because of its potential as a fuel for fusion reactors. The abundance of ${ }^{3} \mathrm{He}$ depends on surface maturity, the relative amount of solar wind fluence, and titanium content. (Ilmenite retains helium much more efficiently than other major lunar minerals.) Johnson et al (1999) combined global maturity and titanium maps from CSR with a solar wind fluence model that accounts for the shielding effects of the Earth's magnetotail to produce near global estimates of ${ }^{3} \mathrm{He}$ abundance in the regolith. Mature mare regions with high titanium content are proposed to contain the highest ${ }^{3} \mathrm{He}$ abundances.

While the Moon occulted the Sun, the Clementine star-tracker cameras mapped the inner zodiacal light (broadband 440-1100 nm) from 0.05 to 0.6 AU (Hahn et al 2002). Zodiacal light is sunlight reflected by interplanetary dust and provides 
a measure of radial and vertical variations in dust density. A simple model attributes the zodiacal light to three dust populations with distinct inclinations; dust from asteroids and Jupiter-family comets, dust from Halley-type comets, and dust from Oort cloud comets (Hahn et al 2002). Interplanetary dust represents samples of small bodies from different regions of the solar system, and thus holds information concerning conditions in various parts of the solar nebula where the larger bodies subsequently formed.

Clementine global lunar albedo estimates were used to calculate spacecraft accelerations due to albedo radiation pressure (Floberghagen et al 1999). Spacecraft accelerations due to albedo forces may be $20 \%$ of accelerations induced by direct solar radiation. The latter is symmetrical over the lunar surface when viewed over one full orbital revolution. Since albedo forces are not symmetrical, they depend on surface materials and topography; there are cumulative, long-term effects of lunar albedo force on the orbit of low satellites. The effect is quantified as 1-2 meters for one week arcs up to 10 meters for a one month arc. The albedo force is also shown to have an effect of 5-10 mGal for global gravity anomalies. This effect will be an important consideration when low satellite-to-satellite tracking decreases gravity induced orbital errors thus leaving albedo force as a significant source of error (Floberghagen et al 1999).

The Clementine Charged Particle Telescope (CPT) measured the fluxes of energetic electrons and protons during solar energetic events and magnetospheric disturbances (Baker 1997). Charged particle fluxes are of interest for solar-cell damage, sensor background effects, radiation effects, and the interaction of the Moon with the Earth's magnetotail. CPT data were also used as part of a multi-spacecraft study of interplanetary disturbances and their effects on the magnetosphere. The CPT detected the passage of an interplanetary shock on 21 February 1994 and provided good data on the shock passage timing and energetic proton energy spectrum (Baker 1997).

\section{Lunar Prospector and Clementine}

Lunar Prospector (LP) orbited the Moon in 1998-1999 and measured gamma rays and neutrons from the lunar surface at a scale of 30-150 km/pixel and provided the means to derive elemental abundance maps. The LP gamma ray data have been reduced to $5^{\circ}$ maps $(150 \mathrm{~km} /$ pixel) for O, Si, Ti, $\mathrm{Al}, \mathrm{Fe}, \mathrm{Mg}, \mathrm{Ca}, \mathrm{U}, \mathrm{K}$, and Th. Analysis of the neutron spectrometer measurements provides $2^{\circ}$ maps $(60 \mathrm{~km} /$ pixel) of $\mathrm{Sm}, \mathrm{Ti}, \mathrm{K}$, and H. Low orbit data acquired at the end of the mission allowed improvements in resolution to $1^{\circ}$ maps (30 km/pixel) for Th, Fe, and H. Lunar Prospector elemental maps, albeit at low resolution, place the Clementine results in a broader geochemical context (Haskin et al 2000; Jolliff et al 2000a; Chevrel et al 2002a, 2002b; Lawrence et al 2002) and provide an independent check on the CSR derived FeO and $\mathrm{TiO}_{2}$ values (Elphic et al 1998, 2000). The Clementine resolution (100-500 m) allows a direct link between spectral data and geochemical/ mineralogical analyses of Apollo and Luna samples. Areas where the compositions derived from orbital measurements and samples diverge have served as a catalyst for detailed analysis (Elphic et al 2002). LP-NS estimates of $\mathrm{TiO}_{2}$ abundance are significantly lower (by up to a factor of two) than Clementine derived abundances (Elphic et al 2000, 2002). This discrepancy may be due to one or more of the following: the poorly understood effect of glasses in soil optical properties; the complexity of opaque mineral reflectance; spectral interferences from minerals, such as the olivine suite; or variations in the $\mathrm{Ti}^{3+}-\mathrm{Ti}^{4+}$ ratio. The Clementine data have also been used to place constraints on the response function of both the Lunar Prospector gamma-ray and neutron spectrometers (Elphic et al 2000; Lawrence et al 2002). The sizes of many lunar compositional features are below the resolution of the gamma-ray spectrometer $(30-60 \mathrm{~km} /$ pixel). Thus, the concentrations of $\mathrm{Th}$ and $\mathrm{K}$ in these small features cannot be confidently derived solely with Lunar Prospector data. However, small scale albedo and compositional anomalies $\left(\mathrm{FeO}, \mathrm{TiO}_{2}\right)$ observed in the much higher resolution Clementine data correspond with compositional anomalies in the gamma-ray data. Integrating the two datasets allows subpixel modeling of thorium abundances resulting in higher resolution compositional interpretations than is possible with LP data alone (Lawrence et al 2003, 2005).

Five remote sensing parameters (albedo Clementine 750 nm, Lunar Prospector maps of Th, and $\mathrm{FeO}$, ratio of epithermal to thermal neutrons, and flux of fast neutrons) were analyzed to characterize broad scale heterogeneities of the crust (Feldman et al 2002). The symmetry axes of the five parameters cluster about the center of the putative Procellarum basin, a feature so large that its formation would have effected the composition of the upper crust and possibly produced the lunar compositional asymmetry we observe today. However, there is no convincing physical evidence for a Procellarum impact basin in the form of topography or crustal thickness estimated from Clementine altimeter data (Neumann et al 1996).

Before Clementine, lunar terranes were classified as either highland or mare based on albedo and 
surface smoothness. Global geochemical data from Clementine and Lunar Prospector revealed three distinct lunar terranes whose geochemistry and petrology make them geologically unique (Jolliff et al 2000b). The boundaries of these terranes are determined from Clementine $\mathrm{FeO}$ maps and Lunar Prospector Th maps. The Procellarum KREEP Terrane (PKT) is defined by high Th concentrations and coincides with the outer boundaries of Oceanus Procellarum. The Feldspathic Highlands Terrane (FHT) covers $60 \%$ of the lunar surface and is defined by low $\mathrm{FeO}$ content. The South Pole-Aitken Terrane (SPAT) is characterized by high $\mathrm{FeO}$ content and corresponds to the South Pole-Aitken basin. Geochemical, geophysical, and petrologic data indicate that each terrane experienced a fundamentally different geologic evolution.

Clementine $\mathrm{FeO}$ abundance maps, Lunar Prospector elemental abundance maps, and Apollo sample return analyses were used to characterize the origin of materials in the lunar regolith across the entire Moon (Korotev and Gillis 2001). A major conclusion of this work was that KREEP material is not native to the highlands, but rather represents a distinct unit of mafic material excavated during the Imbrium impact and redistributed across broad expanses of the nearside (i.e., sampled at Apollo 16). Korotev and Gillis (2001) also found that titanium in picritic glasses may be abundant enough to alter CSR estimates of titanium abundance.

Comparative analysis of CSR derived optical maturity and $\mathrm{TiO}_{2}$ content and regolith hydrogen content inferred from LP-NS epithermal* neutron counts (where epithermal* ${ }^{*}=$ epithermal $-0.057 \times$ thermal neutrons) indicates spatial variations in epithermal* neutrons outside the polar regions (Johnson et al 2002). Many of these non-polar high epithermal* regions (low hydrogen) correspond to Copernican-age impact craters thus showing that interpretation of volatile reserves on the Moon must include analyses of relative age of potential host material.

\section{Topography and gravity}

Until Clementine, knowledge of lunar topography and gravity was non-uniform - little of the farside was measured outside of the Apollo equatorial zone. Clementine laser ranging and high-resolution S-band tracking combined with historic tracking of Lunar Orbiter and Apollo spacecraft allowed the construction of the first global lunar shape (GLTM2) and gravity (GLGM2) models (Zuber et al 1994; Lemoine et al 1997; Smith et al 1997). Early results confirmed the existence of degraded basins, such as the $2500 \mathrm{~km}$ diameter South PoleAitken (SPA) basin, showed that large parts of the highlands are in near-isostatic equilibrium, and identified an apparent crustal thinning under some basins. The Clementine ranging also showed that the Moon has a total relief of over $16 \mathrm{~km}$, the greatest single topographic excursion $(\sim 12 \mathrm{~km})$ lies in the SPA basin.

Clementine LIDAR derived global digital elevation model (DEM) revealed that the lowest elevations in the Serenitatis mare surface occur near the margins of the basin. This was a surprising result in that independent thickness estimates show the mare to be thickest in the interior of the basin, thus models of isostatic compensation place the lowest elevation in the basin center. The unexpected long wavelength topographic expression of Mare Serenitatis may indicate subsidence dominantly the result of basin topography and preexisting zones of lithospheric weakness rather than simple loading by thick deposits of dense mare material (Watters and Konopliv 2001). Clementine LIDAR has also been used to validate high resolution Earth-based radar topography (Margot et al 1999).

Workers investigated the structure of lunar impact basins using Clementine topography data (GLTM2) to apply a Bouguer correction to the Clementine lunar gravity field (GLGM2) (Neumann et al 1996; Wieczorek and Phillips 1998, 1999). They modeled the resulting Bouguer anomalies, corrected for mare fill, as variations on the lunar Moho, assuming a constant density mantle and crust. The difference between the inferred Moho topography and the surface topography is interpreted as the thickness of the lunar crust. Both mare and nonmare basins are characterized by a centrally thinned crust surrounded by rings of thickened crust lying mostly within the basin rims. Many mascon basins (Neumann et al 1996) show that both mare fill and mantle uplift play significant roles in forming the mascon anomalies. These observations indicate a deep structural component to lunar impact basins and show that some basins were not in isostatic equilibrium prior to mare emplacement, indicating a strong lithosphere. Even after the mare load on the surface is removed (numerically), some basins appear to be in a superisostatic state (Neumann et al 1996; Wieczorek and Phillips 1999). This model prediction is supported by the discovery of mascon basins that do not possess any significant mare fill - such gravity anomalies remain mysterious. Later work using the same data (Arkani-Hamed 1998, 1999) revisited the explanations for the negative correlation between topography and gravity and suggest that lunar mascons are dominantly the result of mare fill and that they are dynamically supported today 
but were most likely undergoing viscous deformation until about 3 billion years ago. Analyses by von Frese et al (1997) and Potts and von Frese (2003a, 2003b), using a Cartesian spectral approach, are consistent with the gravity signatures of mascon basins being due to a combination of an uplifted moho and mare basalt fill. Ping and coworkers (2003) determined a lunar topography model NLT180A, a 180 degree spherical harmonic expansion that shows good agreement with GLTM2 model and may provide higher frequency information.

The near global $\left(70^{\circ} \mathrm{S}\right.$ to $\left.70^{\circ} \mathrm{N}\right)$ coverage of Clementine LIDAR measurements revealed the depths of most large impact basins. The new basin dimensions reveal a power law relation between depth and diameter for large impact basins with a shallower slope than the previously identified power law relations for simple and complex craters (Williams and Zuber 1998). From the power law depth relation the original depth of mare filled basins can be estimated. The difference between the predicted unfilled depth and the depth measured from Clementine topography data, correcting for subsidence due to the high density mare material, yields an estimate of mare thickness and volume. This technique depends on the assumption that basins have not undergone any significant amount of viscous relaxation, and thus the inferred mare thicknesses may be overestimated for some basins close to the PKT, such as Imbrium and Serenitatis (see also Wieczorek and Phillips 1999).

Wieczorek and Phillips (1997) used Clementine gravity and topography, constrained by seismic and petrologic data (including crustal density estimated from CSR derived global iron abundance maps), to investigate three models of the structure and compensation of the lunar highland crust. The single-layer Pratt compensation model is considered inconsistent with current data because typical highland variations in $\mathrm{FeO}(3-6 \mathrm{wt} \%)$ result in density variations that are not consistent with the observed low frequency gravity signatures. Both single-layer and dual-layer Airy compensation models are consistent with the constraints and both models suggest a vertically stratified crust with the intracrustal interface consistent with the $20 \mathrm{~km}$ seismic discontinuity determined by Apollo data. In later work, Clementine topography and gravity were used to evaluate four crustal thickness models of the Moon (Wieczorek and Phillips 1998). Of these four, only two gave plausible results: a single layer uniform density model and a dual layered model with thickness variations of both layers. In the light of geochemical, seismic, and geophysical evidence of a stratified lunar crust the authors prefer the dual layered model. This model (updated with Lunar Prospector gravity data) combined with the compositions of central peaks of craters within impact basins constrains the composition of the upper and lower crust (Wieczorek and Zuber 2001). If the expected depth of origin of the central peak was greater than the lower crustal depth predicted by the model then it was assumed that the composition of the central peak represented the lower crust. While the central peak compositions and crustal thickness modeling were consistent with a crust that was roughly stratified into upper anorthositic and lower noritic layers, the authors suggested that plausible crustal formation models would have resulted instead in a continuously zoned composition.

Clementine LIDAR, gravity, and CSR derived iron and titanium abundances were used to test the hypothesis that magma buoyancy is the predominant factor that controls whether basaltic magmas will erupt on the lunar surface or form intrusions (Wieczorek et al 2001). Global altimetry data from Clementine allowed reevaluation of the traditional hypothesis that lunar basalts occur preferentially where the elevation is low or the crust is thin. LIDAR altimetry showed several contradictions to this hypothesis (South Pole-Aitken basin and Oceanus Procellarum) and suggested that some other factor is at work. Wieczorek et al (2001) computed the liquidus densities of mare basalts from the combined weights of iron and titanium from CSR derived global iron and titanium maps. Based on the hypothesis that the lower crust is more mafic, and hence denser, than the upper crust, wherever large basins excavated the entire upper crust, any type of basalt could have erupted based on buoyancy considerations alone. Eruptions in the highlands could have occurred if the basalts were less dense than typical, such is the case for low-Fe and/or high Al basalts. The calculated liquidus densities show that erupted magmas typically are less dense than the lower noritic crust in basins where impact has removed much or all of the upper anorthositic crust. The lack of mare in SPA is interpreted as a manifestation of lateral variations in magma production. The relatively dense magmas erupted in Oceanus Procellarum could be explained either by unusually high magma temperatures (with lower density) due to high concentrations of KREEP, or due to an atypical, and more mafic crustal composition.

Frame-to-frame overlap of the UVVIS global dataset was leveraged (Cook et al 1996, 2000) to produce stereo-based topographic maps at resolutions of $2-5 \mathrm{~km} /$ pixel (Oberst et al 1996). Improving upon the lower resolution LIDAR topography, these data have revealed previously unknown ancient degraded basins improving our 
knowledge of cratering rates in the early solar system. Clementine LIDAR data were also used to confirm previously identified multiring impact basins and recognized two previously unidentified basins (Spudis et al 1994). Finally Clementine UVVIS images have served to improve the positional accuracy of the Apollo landing sites (Davies and Colvin 2000).

\section{Polar studies}

Theory, radar measurements and neutron measurements suggest that deposits of ice may occur in permanently shadowed regions at the lunar poles (figure 5). Polar massifs illuminated for anomalously extended periods are prime candidates for future lunar bases. Thus much effort has gone into the analysis of Clementine data to better characterize illumination conditions of the lunar polar regions. Due to Clementine's near polar orbit, lighting conditions were recorded at the pole every orbit with the UVVIS camera. Combining these repetitive observations over a complete lunar day allows the identification of locations of permanent shadow and near permanent light. At the time of the Clementine mission the Moon was in southern winter and northern summer (Shoemaker et al 1994). Thus derived lighting maps (Shoemaker et al 1994; Bussey et al 1999) more accurately map permanent shadows and near-permanent illumination in the northern and southern hemispheres, respectively. It was found that two peaks near the south pole, only $10 \mathrm{~km}$ apart, collectively receive sunlight for over $98 \%$ of a southern winter (Bussey et al 1999). A similar analysis showed that a few small peaks receive sunlight for $100 \%$ of a lunar summer near the north pole (Bussey et al 2005), however lighting conditions of these northern peaks remain unknown during winter. Clementine UVVIS images were used with a simple crater morphology model to simulate illumination conditions and predict the amount of shadow based on crater diameter and latitude (Bussey et al 2003). The shadow model was applied to all mapped polar craters giving a lower estimate of permanently shadowed area of $7500 \mathrm{~km}^{2}$ for the north pole and $6500 \mathrm{~km}^{2}$ for the south pole. Zuber and Smith (1997) used Clementine LIDAR topography to constrain southern hemisphere permanent shadow estimates. They conclude that areas of permanent shadow are constrained to craters with diameter less than $80 \mathrm{~km}$.

The possibility that ice may exist in permanently shadowed craters near the lunar poles was suggested before spacecraft reached the Moon. Though the Clementine spacecraft had no instruments specifically designed to address this possibility, ad hoc use of the main transmitter permitted the execution of a bi-static radar experiment, albeit with less than optimal signal-to-noise (Nozette et al 1996), that could in theory detect ice deposits. During several orbits as the spacecraft approached the pole a constant signal was bounced off a region on the surface and received on Earth. Subsequent analysis of the strength and polarization properties of the received signal led to the hypothesis that a low-loss volume scatterer existed near the south pole, possibly within Shackleton crater (Nozette et al 1996). Other workers hypothesized that this same signal was due to unusual surface roughness configurations, or simply noise in the dataset (Simpson and Tyler 1999). Lunar Prospector neutron spectrometer results showed large hydrogen enhancements near both poles, further stoking the controversy concerning the possibility of large-scale reservoirs of water ice stored in polar craters. An integration of refined Clementine bistatic radar results with LP neutron spectrometer data again showed a correlation of Shackleton crater with derived parameters consistent with large reservoirs of water ice (Nozette et al 2001), though the authors noted that new data are needed to definitively settle the question of ice at the lunar poles.

A search for the spectral signature of $\mathrm{H}_{2} \mathrm{O}$ in multiple-scattered radiation from permanently shadowed craters in UVVIS and NIR images was negative (McConnochie et al 2002). However, this negative result does not exclude the possibility of impure or buried water ice inside the permanently shadowed craters.

\section{Photometry}

The Clementine UVVIS camera was able to image the surface down to $0^{\circ}$ phase allowing a detailed analysis of the 'opposition surge'. It was found that the surface brightness increased $\sim 40 \%$ from $4^{\circ}$ to $0^{\circ}$ phase with a slight wavelength dependence (greater effect at shorter wavelengths), leading to the conclusion that the opposition surge is dominantly controlled by shadow hiding and not coherent backscatter (Buratti et al 1996).

Through comparison with ground-based measurements Hillier et al (1999) found that the USGS UVVIS global mosaic reflectance map values are too large, and they derived a correction factor of 0.532 for all bands. Shkuratov and coworkers (2001) later derived a similar absolute brightness coefficient. Additionally, Hillier et al (1999) derived a new empirical phase function for highlands and mare for each UVVIS filter. Finally they conclude that the lunar opposition surge is predominantly the result of shadow hiding but that coherent backscatter contributes significantly at low phase 


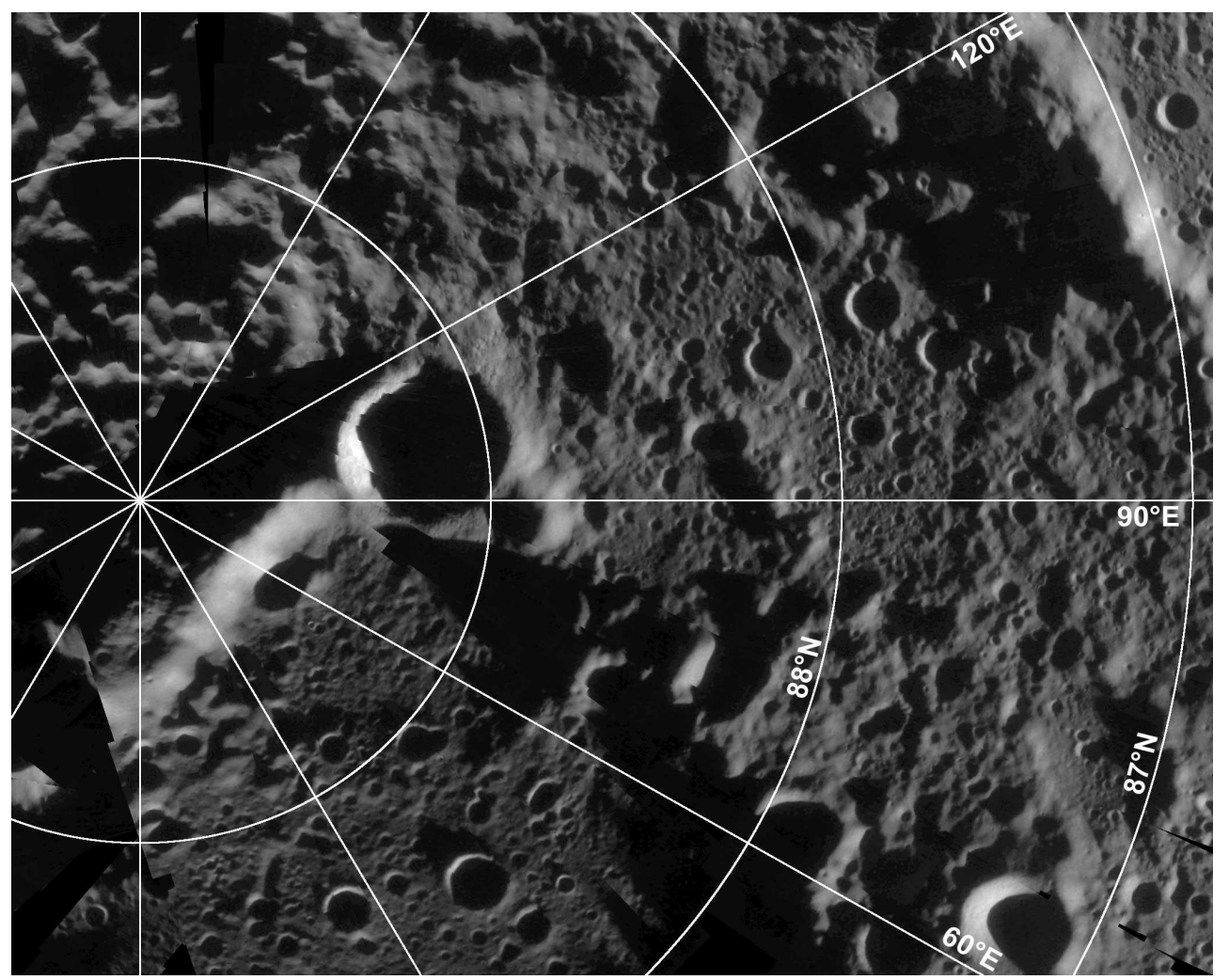

Figure 5. The HIRES camera acquired nearly complete coverage of both the north and south pole regions. In this northern summer view, numerous small and large candidate permanently shadowed craters can be seen, the largest being centered at $89.3^{\circ} \mathrm{N}, 112^{\circ} \mathrm{E}$.

angles in terrains with higher reflectance. In a similar study Shkuratov and coworkers (1999) also proposed that the opposition surge is partially due to coherent backscatter. The Clementine observations also led to the conclusion that the magnitude and nature of the opposition surge is terrane dependant (Hillier et al 1999; Kreslavsky et al 2000; Shkuratov et al 1999; Yakota et al 1999).

\section{Thermal mapping}

Lawson and coworkers (2000) derived a calibration for the LWIR data and demonstrated that the Lambertian temperature model of $\cos ^{1 / 4}(\mathrm{i})$ best approximates nadir-looking temperatures. The LWIR data set also indicates that dayside lunar thermal emission is governed by albedo, the intensity of solar radiation and phase angle. Lawson and Jakosky (2001) examined the correlation between Clementine LWIR temperatures and Clementine UVVIS $750 \mathrm{~nm}$ reflectances and concluded that at low phase angles single scattering albedo dominates temperature variations and at large phase angles surface roughness dominates temperature variations. Colwell and Jakosky (2002) found that for large solar incidence angles surface roughness significantly alters the slope of a thermal infrared spectrum, shifting the location of the Christiansen frequency.

\section{Lunar transient phenomena}

Clementine UVVIS data were acquired of several regions on the Moon twice. Of these areas four were reported to have undergone Lunar Transient Phenomena (LTP) between acquisitions of the repeat images. However no evidence of LTP (Buratti et al 2000) were found through comparison of before and after frames. Buratti and Johnson (2003) used Clementine multispectral images to identify a fresh impact crater whose formation was supposedly captured in a 1953 telescopic photograph by amateur astronomer Dr. Leon H Stuart. Subsequently, this finding was challenged because the crater identified by Buratti and Johnson appears on several telescopic plates dating back to 1919, well before Stuart took his exposure in 1953 (Beatty 2003). Clementine optical maturity images show the crater in question is not the youngest in the vicinity and is not younger than craters dated by sample returns, indicating it may not be a particularly young crater (Blewett et al 2005). 


\section{Interplanetary comparisons}

Blewett and coworkers (1997b) applied the lunar spectral iron determination developed from Clementine data by Lucey et al (1995) to earthbased telescopic spectra of Mercury to investigate the composition of the planet's surface. They concluded that Mercury's surface has very low iron $(\sim 3 \mathrm{wt} \%)$ and low titanium $(<\sim 1 \mathrm{wt} \%)$ abundances. Using maps of iron abundance and optical maturity produced from Clementine data, areas of mature lunar anorthosite were located and their Clementine UVVIS spectra compared to Earthbased spectra of Mercury. The spectra of both areas are similar, consistent with previous proposals that lunar mature pure anorthosite is a useful analog for Mercury (Blewett et al 2002).

Warell and Blewett (2004) used simultaneous earth-based telescopic spectra of Mercury and the Moon to apply the Lucey iron and titanium abundance models to Mercury. They found iron and titanium abundances lower than previous studies $\left(\sim 1.2 \mathrm{wt} \% \mathrm{FeO}\right.$ and $\left.\sim 0 \mathrm{wt} \% \mathrm{TiO}_{2}\right)$, while cautioning that issues such as differences in maturation states and unresolved calibration residuals result in unknown but relatively large error bars.

Murchie and coworkers (2002) applied the Lucey $\mathrm{FeO}$ method to high resolution NEAR multispectral image data of the asteroid 433 Eros and found significant differences in spectral behavior that they attributed to differences in space weathering environments between Eros and the Moon.

\section{Summary, conclusions, and future lunar exploration}

The CSR derived modal mineralogy and composition maps have fundamentally reshaped the scientific community's view of the evolution of the lunar crust in several major respects. First, prior to Clementine, the Apollo 16 landing site was viewed as typical highlands terrane. The CSR revealed that the Apollo 16 site is actually anomalously rich in $\mathrm{FeO}$ (6 wt\% versus $3-4 \mathrm{wt} \%$ found in much of the farside highlands) (Lucey et al 1995; Tompkins and Pieters 1999). Second, the CSR spectral parameter maps delineated and quantified the geochemical importance of the South PoleAitken (SPA) basin, first identified as an albedo anomaly in the low resolution Galileo multispectral data. Finally, the CSR data showed that some mare units contain unexpected variations in mafic (i.e., olivine and pyroxene) mineralogy (Lucey 2004; Staid and Pieters 2001). Clementine UVVIS data unambiguously showed the lunar crust to be more diverse than indicated by the Apollo sample collection - the Moon is no longer viewed as a twoterrane planet (mare vs. highlands).

Clementine proved the value of high resolution remotely sensed visible to near-infrared measurements combined with analyses of returned samples, gravity, topography, high-resolution images, and gamma-ray/neutron spectroscopy (Jolliff et al 2000a; McCallum 2001). Results from the Clementine mission now set the stage for future lunar datasets:

- High SNR (>200) and high resolution spectroscopy (> $50 \mathrm{~m} /$ pixel locally).

- High resolution topography (3 times better than spectral data) to allow detailed analysis of massifs and craters.

- Precise farside tracking for gravity.

- Morphologic imaging $\left(70^{\circ}\right.$ inclination and $10 \mathrm{~m} /$ pixel global, $50 \mathrm{~cm} /$ pixel local).

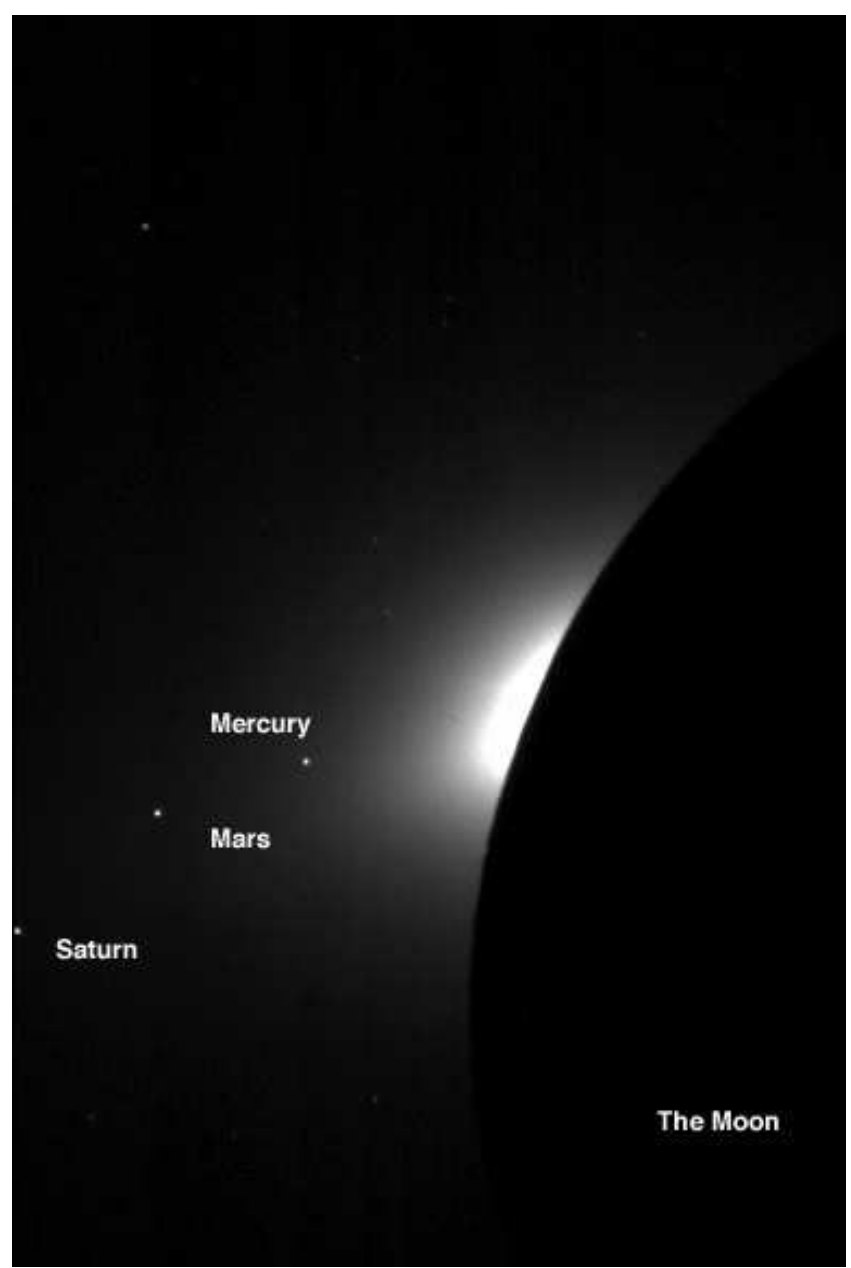

Figure 6. Great strides in our knowledge of the Moon have occurred in the past 40 years, though much of the Moon's geology, evolution, and origin remain unknown. The advent of the Clementine data sparked a renaissance in lunar geology spurring progress in understanding problems remaining from the Apollo era applicable to not only our understanding of the Moon, but also formation conditions in the early Solar System and how terrestrial planets evolve over time (Clementine Star tracker frame lba0063v.066). 
- Measurement(s) to definitively map and characterize putative polar volatiles.

Clementine also demonstrated the pressing need for returned material from key unsampled units such as the South Pole-Aitken basin. The 2003 NRC Planetary Decadal Report identified a sample return mission from the SPA as a high priority goal for NASA. Such a sample was identified as key to better understanding planet and satellite formation and unraveling the large impactor flux in the first $500 \mathrm{my}$ of the Solar System. The latter problem has fundamental implications for constraining the time that life emerged on the Earth, and possibly other bodies. The rich results from the Clementine mission have shaped science goals and instrument selection for new lunar missions such as SMART-1 and the Lunar Reconnaissance Orbiter (Robinson et al 2005; Shkuratov et al 2003). In addition, Clementine and Lunar Prospector have shown the value of integrated analyses of diverse global datasets to probe fundamental questions concerning the origin and evolution of the Moon and all Solar System bodies. It is clear that as results from future missions are examined they will be integrated with the existing Clementine global data products. Finally, Clementine results will continue to serve the planetary science community as a basis for comparison for future measurements of Mercury, Mars, and beyond (figure 6).

\section{Acknowledgements}

The NASA Planetary Geology and Geophysics program supported this work. Gratitude is extended to M Wieczorek (IPGP) and P Lucey (Univ. of Hawaii) for helpful discussions.

\section{References}

Arkani-Hamed J 1998 The lunar mascons revisited; J. Geophys. Res. 103(E2) 3709-3739.

Arkani-Hamed J, Konopliv A S and Sjogren W L 1999 On the equipotential surface hypothesis of lunar maria floors; J. Geophys. Res. 104(E3) 5921-5931.

Baker D N 1997 Clementine particle measurements in lunar orbit; Adv. Space Res. 19(10) 1587-1591.

Beatty J K 2003 Lunar flash doesn't pan out; Sky and Telescope, June 24.

Blewett D T, Lucey P G, Hawke B R and Jolliff B L 1997a Clementine images of the lunar sample-return stations: Refinement of $\mathrm{FeO}$ and $\mathrm{TiO}_{2}$ mapping techniques; J. Geophys. Res. 102(E7) 16,319-16,325.

Blewett D T, Lucey P G, Hawke B R, Ling G G and Robinson M S 1997b A comparison of Mercurian reflectance and spectral quantities with those of the Moon; Icarus 129(1) 217-231.

Blewett D T and Hawke B R 2001 Remote sensing and geological studies of the Hadley-Apennine region of the Moon; Meteorit. Planet. Sci. 36(5) 701-730.
Blewett D T, Hawke B R and Lucey P G 2002 Lunar pure anorthosite as a spectral analog for Mercury; Meteorit. Planet. Sci. 37(9) 1245-1254.

Blewett D T, Hawke B R and Lucey P G 2005 Lunar optical maturity investigations: A possible recent impact crater and a magnetic anamoly; J. Geophys. Res. 110 E04015, doi:10.1029/4002JE002380.

Budney C J and Lucey P G 1998 Basalt thickness in Mare Humorum: The crater excavation method; J. Geophys. Res. 103(E7) 16,855-16,870.

Buratti B J, Hiller J K and Wang M 1996 The lunar opposition surge: Observations by Clementine; Icarus 124(2) 490-499.

Buratti B J, McConnochie T H, Calkins S B, Hillier J K and Herkenhoff K E 2000 Lunar transient phenomena: What do the Clementine images reveal?; Icarus 146(1) 98-117.

Buratti B J and Johnson L L 2003 Identification of the lunar flash of 1953 with a fresh crater on the Moon's surface; Icarus 161(1) 192-197.

Bussey D B J and Spudis P D 1997 Compositional analysis of the Orientale basin using full resolution Clementine data: Some preliminary results; Geophys. Res. Lett. 24(4) 445-448.

Bussey D B J, Spudis P D and Robinson M S 1999 Illumination conditions at the lunar south pole; Geophys. Res. Lett. 26(9) 1187-1190.

Bussey D B J and Spudis P D 2000 Compositional studies of the Orientale, Humorum, Nectaris, and Crisium lunar basins; J. Geophys. Res. 105(E2) 4235-4243.

Bussey D B J, Lucey P G, Steutel D, Robinson M S, Spudis P D and Edwards K D 2003 Permanent shadow in simple craters near the lunar poles; Geophys. Res. Lett. 30(6) 1278, doi:10.1029/2002GL016180.

Bussey D B J, Fristad K E, Schenk P M, Robinson M S and Spudis P D 2005 Constant illumination at the lunar north pole; Nature 434(7035) 842-842.

Campbell B A, Hawke B R and Thompson T W 1997 Regolith composition and structure in the lunar maria: Results of long-wavelength radar studies; J. Geophys. Res. 102(E8) 19,307-19,320.

Chevrel S D, Pinet P C and Head J W 1999 Gruithuisen domes region: A candidate for an extended nonmare volcanism unit on the Moon; J. Geophys. Res. 104(E7) $16,515-16,529$.

Chevrel S D, Pinet P C, Daydou Y and Feldman W C 2002a Integration and comparison of Clementine and Lunar Prospector data: Global scale multielement analysis (Fe, $\mathrm{Ti}$, and Th) of the lunar surface; Solar Sys. Res. 36(6) 458-465.

Chevrel S D, Pinet P C, Daydou Y, Maurice S, Lawrence D J, Feldman W C and Lucey P G $2002 \mathrm{~b}$ Integration of the Clementine UV-VIS spectral reflectance data and the Lunar Prospector gamma-ray spectrometer data: A global-scale multielement analysis of the lunar surface using iron, titanium, and thorium abundances; J. Geophys. Res. 107(E12) 5132, doi:10.1029/2000JE001419.

Clark P E and McFadden L A 2000 New results and implications for lunar crustal iron distribution using sensor data fusion techniques; J. Geophys. Res. 105(E2) 4291-4316.

Colwell J E and Jakosky B M 2002 Effects of topography on thermal infrared spectra of planetary surfaces; J. Geophys. Res. 107(E11) 5106, doi:10.1029/2001JE001829.

Cook A C, Oberst J, Roatsch T, Jaumann R and Acton C 1996 Clementine imagery: Selenographic coverage for cartographic and scientific use; Planet. Space. Sci. 44(10) $1135-1148$.

Cook A C, Watters T R, Robinson M S, Spudis P D and Bussey D B J 2000 Lunar polar topography derived 
from Clementine stereoimages; J. Geophys. Res. 105(E5) $12,023-12,033$.

Craddock R A and Howard A D 2000 Simulated degradation of lunar impact craters and a new method for age dating farside mare deposits; J. Geophys. Res. 105(E8) 20,387-20,401.

Davies M E and Colvin T R 2000 Lunar coordinates in the regions of the Apollo landers; J. Geophys. Res. 105(E8) 20,277-20,280.

Daydou Y H, Pinet P C, Chevrel S and Le Mouelic S 2003 A systematic intercalibration tool between multiband imaging and spot spectra datasets; Planet. Space. Sci. 51(4-5) 309-317.

Duke M B 1998 Lunar polar ice: Implications for lunar development; J. Aero. Engg. 11(4) 124-128.

Eliason E M, Lee E M, Becker T L, Weller L A, Isbell C E, Staid M I, Gaddis L R, McEwen A S, Robinson M S, Duxbury T, Steutel D, Blewett D T and Lucey P G 2003 A near-infrared (NIR) global multispectral map of the Moon from Clementine; Lunar and Planetary Science Conference XXXIV, Houston, TX, USA \#2093.

Elphic R C, Lawrence D J, Feldman W C, Barraclough B L, Maurice S, Binder A B and Lucey P G 1998 Lunar Fe and Ti abundances: Comparison of Lunar Prospector and Clementine data; Science 281(5382) 1493-1496.

Elphic R C, Lawrence D J, Feldman W C, Barraclough B L, Maurice S, Binder A B and Lucey P G 2000 Lunar rare earth element distribution and ramifications for $\mathrm{FeO}$ and $\mathrm{TiO}_{2}$ : Lunar Prospector neutron spectrometer observations; J. Geophys. Res. 105(E8) 20,333-20,345.

Elphic R C, Lawrence D J, Feldman W C, Barraclough B L, Gasnault O M, Maurice S, Lucey P G, Blewett D T and Binder A B 2002 Lunar Prospector neutron spectrometer constraints on $\mathrm{TiO}_{2}$; J. Geophys. Res. 107(E4) 5024, doi:10.1029/2000JE001460.

Feldman W C, Gasnault O, Maurice S, Lawrence D J, Elphic R C, Lucey P G and Binder A B 2002 Global distribution of lunar composition: New results from Lunar Prospector; J. Geophys. Res. 107(E3) 5016, doi:10.1029/2001JE001506.

Fischer E M and Pieters C M 1996 Composition and exposure age of the Apollo 16 Cayley and Descartes regions from Clementine data: Normalizing the optical effects of space weathering; J. Geophys. Res. 101(E1) 2225-2234.

Floberghagen R, Visser P and Weischede F 1999 Lunar albedo force modeling and its effect on low lunar orbit and gravity field determination; Adv. Space Res. 23(4) 733-738.

Gaddis L R, Hawke B R, Robinson M S and Coombs C 2000 Compositional analyses of small lunar pyroclastic deposits using Clementine multispectral data; J. Geophys. Res. 105(E2) 4245-4262.

Gaddis L R, Staid M I, Tyburczy J A, Hawke B R and Petro N E 2003 Compositional analyses of lunar pyroclastic deposits; Icarus 161(2) 262-280.

Ghent R R, Leverington D W and Campbell B A 2005 Earth-based observations of radar-dark crater haloes on the Moon: Implications for regolith properties; J. Geophys. Res. 110(E2) E02005, doi:10.1029/2004JE002366.

Giguere T A, Taylor G J, Hawke B R and Lucey P G 2000 The titanium contents of lunar mare basalts; Meteorit. Planet. Sci. 35(1) 193-200.

Giguere T A, Hawke B R, Blewett D T, Bussey D B J, Lucey P G, Smith G A, Spudis P D and Taylor G J 2003 Remote sensing studies of the Lomonosov-Fleming region of the Moon; J. Geophys. Res. 108(E11) 5118, doi:10.1029/2003JE002069.
Gillis J J and Spudis P D 2000 Geology of the Smythii and Marginis region of the Moon: Using integrated remotely sensed data; J. Geophys. Res. 105(E2) 4217-4233.

Gillis J J and Jolliff B L 2003 A revised algorithm for calculating $\mathrm{TiO}_{2}$ from Clementine UVVIS data: A synthesis of rock, soil, and remotely sensed $\mathrm{TiO}_{2}$ concentrations; J. Geophys. Res. 108(E2) 5009, doi:10.1029/2001JE001515.

Gillis J J, Jolliff B L and Korotev R L 2004 Lunar surface geochemistry: Global concentrations of Th, K, and FeO as derived from Lunar Prospector and Clementine data; Geochim. Cosmochim. Acta 68(18) 3791-3805.

Grier J A and McEwen A S 1997 The small-comet hypothesis: An upper limit to the current impact rate on the Moon; Geophys. Res. Lett. 24(24) 3105-3108.

Grier J A, McEwen A S, Lucey P G, Milazzo M and Strom R G 2001 Optical maturity of ejecta from large rayed lunar craters; J. Geophys. Res. 106(E12) $32,847-32,862$.

Hahn J M, Zook H A, Cooper B and Sunkara B 2002 Clementine observations of the zodiacal light and the dust content of the inner solar system; Icarus 158(2) 360-378.

Haskin L A, Gillis J J, Korotev R L and Jolliff B L 2000 The materials of the lunar Procellarum KREEP Terrane: A synthesis of data from geomorphological mapping, remote sensing, and sample analyses; J. Geophys. Res. 105(E8) 20,403-20,415.

Hawke B R, Giguere T A, Blewett D T, Lucey P G, Smith G A, Taylor G J and Spudis P D 2002 Igneous activity in the southern highlands of the Moon; J. Geophys. Res. 107(E12) 5122, doi:10.1029/2000JE001494.

Hawke B R, Lawrence D J, Blewett D T, Lucey P G, Smith G A, Spudis P D and Taylor G J 2003a Hansteen Alpha: A volcanic construct in the lunar highlands; J. Geophys. Res. 108(E7) 5069, doi:10.1029/2002JE002013.

Hawke B R, Peterson C A, Blewett D T, Bussey D B J, Lucey P G, Taylor G J and Spudis P D 2003b Distribution and modes of occurrence of lunar anorthosite; J. Geophys. Res. 108(E6) 5050, doi:10.1029/2002JE001890.

Hawke B R, Blewett D T, Lucey P G, Smith G A, Bell J F, Campbell B A and Robinson M S 2004 The origin of lunar crater rays; Icarus $\mathbf{1 7 0 ( 1 ) ~ 1 - 1 6 . ~}$

Head J W, Wilson L and Weitz C M 2002 Dark ring in southwestern Orientale Basin: Origin as a single pyroclastic eruption; J. Geophys. Res. 107(E1) 5001, doi:10.1029/2000JE001438.

Heather D J and Dunkin S K 2002a A stratigraphic study of southern Oceanus Procellarum using Clementine multispectral data; Planet. Space. Sci. 50(14-15) $1299-1309$.

Heather D J and Dunkin S K 2002b Crustal stratigraphy of the Al-Khwarizmi-King/Tsiolkovsky-Stark region of the lunar farside as seen by Clementine; Planet. Space. Sci. 50(14-15) 1311-1321.

Heather D J and Dunkin S K 2003 Geology and stratigraphy of King crater, lunar farside; Icarus 163(2) 307-329.

Heather D J, Dunkin S K and Wilson L 2003 Volcanism on the Marius Hills plateau: Observational analyses using Clementine multispectral data; J. Geophys. Res. 108(E3) 5017, doi:10.1029/2002JE001938.

Heiken G H, Vaniman D T and French B M 1991 Lunar Sourcebook: A User's Guide to the Moon; Cambridge University Press, Cambridge, pp. 736.

Hiesinger H, Head $\mathrm{J}$ W, Wolf $\mathrm{U}$, Jaumann $\mathrm{R}$ and Neukum G 2003 Ages and stratigraphy of mare basalts in Oceanus Procellarum, Mare Nubium, Mare Cognitum, 
and Mare Insularum; J. Geophys. Res. 108(E7) 5065, doi:10.1029/2002JE001985.

Hillier J K, Buratti B J and Hill K 1999 Multispectral photometry of the Moon and absolute calibration of the Clementine UV/Vis camera; Icarus 141(2) 205-225.

Johnson J R, Swindle T D and Lucey P G 1999 Estimated solar wind-implanted helium-3 distribution on the Moon; Geophys. Res. Lett. 26(3) 385-388.

Johnson J R, Feldman W C, Lawrence D J, Maurice S, Swindle T D and Lucey P G 2002 Lunar Prospector epithermal neutrons from impact craters and landing sites: Implications for surface maturity and hydrogen distribution; J. Geophys. Res. 107(E2) 5008, doi:10.1029/2000JE001430.

Jolliff B L 1999 Clementine UVVIS multispectral data and the Apollo 17 landing site: What can we tell and how well?; J. Geophys. Res. 104(E6) 14,123-14,148.

Jolliff B, Gaddis L R, Ryder G, Neal C R, Shearer K, Elphic R C, Johnson J R, Keller L P, Korotev R L, Lawrence D J, Lucey P G, Papike J J, Pieters C M, Spudis P D and Taylor L A 2000a New views of the Moon; Eos 81(31) 349,354-349,355.

Jolliff B L, Gillis J J, Haskin L A, Korotev R L and Wieczorek M A 2000b Major lunar crustal terranes: Surface expressions and crust-mantle origins; J. Geophys. Res. 105(E2) 4197-4216.

Kodama S and Yamaguchi Y 2003 Lunar mare volcanism in the eastern nearside region derived from Clementine UV/VIS data; Meteorit. Planet. Sci. 38(10) 1461-1484.

Korotev R L and Gillis J J 2001 A new look at the Apollo 11 regolith and KREEP; J. Geophys. Res. 106(E6) $12,339-12,353$

Kreslavsky M A, Shkuratov Y G, Velikodsky Y I, Kaydash V G, Stankevich D G and Pieters C M 2000 Photometric properties of the lunar surface derived from Clementine observations; J. Geophys. Res. 105(E8) 20,281-20,295.

Kreslavsky M A and Shkuratov Y G 2003 Photometric anomalies of the lunar surface: Results from Clementine data; J. Geophys. Res. 108(E3) 5015, doi:10.1029/2002JE001937.

Lawrence D J, Feldman W C, Elphic R C, Little R C, Prettyman T H, Maurice S, Lucey P G and Binder A B 2002 Iron abundances on the lunar surface as measured by the Lunar Prospector gamma-ray and neutron spectrometers; J. Geophys. Res. 107(E12) 5130 doi:10.1029/2001JE001530.

Lawrence D J, Elphic R C, Feldman W C, Prettyman T H, Gasnault O and Maurice S 2003 Small-area thorium features on the lunar surface; J. Geophys. Res. 108(E9) 5102, doi:10.1029/203JE002050.

Lawrence D J, Hawke B R, Hagerty J J, Elphic R C, Feldman W C, Prettyman T H and Vaniman D T 2005 Evidence for a high-Th, evolved lithology on the Moon at Hansteen Alpha; Geophys. Res. Lett. 32(7) L07201, doi:10.1029/2004GL022022.

Lawson S L, Jakosky B M, Park H S and Mellon M T 2000 Brightness temperatures of the lunar surface: Calibration and global analysis of the Clementine long-wave infrared camera data; J. Geophys. Res. 105(E2) 4273-4290.

Lawson S L and Jakosky B M 2001 Lunar surface thermophysical properties derived from Clementine LWIR and UVVIS images; J. Geophys. Res. 106(E11) 27,911-27,932.

Le Mouelic S, Langevin Y and Erard S 1999a The distribution of olivine in the crater Aristarchus inferred from Clementine NIR data; Geophys. Res. Lett. 26(9) $1195-1198$
Le Mouelic S, Langevin Y and Erard S 1999b A new data reduction approach for the Clementine NIR data set: Application to Aristillus, Aristarchus and Kepler; J. Geophys. Res. 104(E2) 3833-3843.

Le Mouelic S, Langevin Y, Erard S, Pinet P, Chevrel S and Daydou Y 2000 Discrimination between maturity and composition of lunar soils from integrated Clementine UV-visible/near-infrared data: Application to the Aristarchus Plateau; J. Geophys. Res. 105(E4) 9445-9455.

Le Mouelic S and Langevin Y 2001 The olivine at the lunar crater Copernicus as seen by Clementine NIR data; Planet. Space. Sci. 49(1) 65-70.

Le Mouelic S, Lucey P G, Langevin Y and Hawke B R 2002 Calculating iron contents of lunar highland materials surrounding Tycho crater from integrated Clementine UV-visible and near-infrared data; J. Geophys. Res. 107(E10) 5074, doi:10.1029/2000JE001484.

Lemoine F G R, Smith D E, Zuber M T, Neumann G A and Rowlands D D 1997 A 70th degree lunar gravity model (GLGM-2) from Clementine and other tracking data; J. Geophys. Res. 102(E7) 16,339-16,359.

Li L and Mustard J F 2000 Compositional gradients across mare-highland contacts: Importance and geological implication of lateral transport; J. Geophys. Res. 105(E8) 20,431-20,450.

Li L and Mustard J F 2003 Highland contamination in lunar mare soils: Improved mapping with multiple end-member spectral mixture analysis (MESMA); J. Geophys. Res. 108(E6) 5053, doi:10.1029/2002JE001917.

Lucey P G, Spudis P D, Zuber M, Smith D and Malaret E 1994 Topographic-compositional units on the Moon and the early evolution of the lunar crust; Science 266(5192) $1855-1858$.

Lucey P G, Taylor G J and Malaret E 1995 Abundance and distribution of iron on the Moon; Science 268(5214) 1150-1153.

Lucey P G, Blewett D T and Hawke B R 1998a Mapping the $\mathrm{FeO}$ and $\mathrm{TiO}_{2}$ content of the lunar surface multispectral imagery; J. Geophys. Res. 103(E2) 3679-3699.

Lucey P G, Taylor G J, Hawke B R and Spudis P D 1998b $\mathrm{FeO}$ and $\mathrm{TiO}_{2}$ concentrations in the South Pole-Aitken basin: Implications for mantle composition and basin formation; J. Geophys. Res. 103(E2) 3701-3708.

Lucey P G, Blewett D T and Jolliff B L 2000a Lunar iron and titanium abundance algorithms based on final processing of Clementine ultraviolet-visible images; J. Geophys. Res. 105(E8) 20,297-20,305.

Lucey P G, Blewett D T, Taylor G J and Hawke B R 2000b Imaging of lunar surface maturity; J. Geophys. Res. 105(E8) 20,377-20,386.

Lucey P G 2004 Mineral maps of the Moon; Geophys. Res. Lett. 31(8) L08701, doi:10.1029/2003GL019406.

Margot J, Campbell D B, Jurgens R F and Slade M A 1999 The topography of Tycho Crater; J. Geophys. Res. 104(E5) 11,875-11,882.

McCallum I S 2001 A new view of the moon in light of data from Clementine and Prospector missions; Earth, Moon and Planets 85-86 253-269.

McConnochie T H, Buratti B J, Hillier J K and Tryka K A 2002 A search for water ice at the lunar poles with Clementine images; Icarus 156(2) 335-351.

McEwen A S, Robinson M S, Eliason E M, Lucey P G, Duxbury T C and Spudis P D 1994 Clementine observations of the Aristarchus region of the Moon; Science 266(5192) 1858-1862.

McEwen A S, Moore J M and Shoemaker E M 1997 The Phanerozoic impact cratering rate: Evidence from the farside of the Moon; J. Geophys. Res. 102(E4) 9231-9242. 
McEwen A S and Robinson M S 1997 Mapping of the moon by Clementine; Adv. Space Res. 19(10) 1523-1533.

Morota T and Furumoto M 2003 Asymmetrical distribution of rayed craters on the Moon; Earth Planet. Sci. Lett. 206(3-4) 315-323.

Murchie S, Robinson M, Clark B, Li H, Thomas P, Joseph J, Bussey B, Domingue D, Veverka J, Izenberg N and Chapman C 2002 Color variations on Eros from NEAR multispectral imaging; Icarus 155(1) 145-168.

Mustard J F, Li L and He G 1998 Nonlinear spectral mixture modeling of lunar multispectral data: Implications for lateral transport; J. Geophys. Res. 103(E8) $19,419-19,425$

Nagumo K and Nakamura A M 2001 Reconsideration of crater size-frequency distribution on the Moon: effect of projectile population and secondary craters; Adv. Space Res. 28(8) 1181-1186.

Neumann G A, Zuber M T, Smith D E and Lemoine F G 1996 The lunar crust: Global structure and signature of major basins; J. Geophys. Res. 101(E7) $16,841-16,863$.

Nozette S et al 1994 The Clementine Mission to the Moon - Scientific overview; Science 266(5192) 1835-1839.

Nozette S, Lichtenberg C L, Spudis P, Bonner R, Ort W, Malaret E, Robinson M and Shoemaker E M 1996 The Clementine bistatic radar experiment; Science 274(5292) 1495-1498.

Nozette S, Spudis P D, Robinson M S, Bussey D B J, Lichtenberg C and Bonner R 2001 Integration of lunar polar remote-sensing data sets: Evidence for ice at the lunar south pole; J. Geophys. Res. 106(E10) 23,253-23,266.

Oberst J, Roatsch T, Zhang W, Cook A C, Jaumann R, Duxbury T, Wewel F, Uebbing R, Scholten F and Albertz J 1996 Photogrammetric analysis of Clementine multi-look angle images obtained near Mare Orientale; Planet. Space. Sci. 44(10) 1123-1133.

Pieters C M, Staid M I, Fischer E M, Tompkins S and He G 1994 A sharper view of impact craters from Clementine data; Science 266(5192) 1844-1848.

Pieters C M, Tompkins S, Head J W and Hess P C 1997 Mineralogy of the mafic anomaly in the South Pole-Aitken basin: Implications for excavation of the lunar mantle; Geophys. Res. Lett. 24(15) 1903-1906.

Pieters C M and Tompkins S 1999 Tsiolkovsky crater: A window into crustal processes on the lunar farside; J. Geophys. Res. 104(E9) 21,935-21,949.

Pieters C M, Head J W, Gaddis L, Jolliff B and Duke M 2001 Rock types of South Pole-Aitken basin and extent of basaltic volcanism; J. Geophys. Res. 106(E11) 28,001-28,022.

Pinet P C, Shevchenko V V, Chevrel S D, Daydou Y and Rosemberg C 2000 Local and regional lunar regolith characteristics at Reiner Gamma Formation: Optical and spectroscopic properties from Clementine and Earthbased data; J. Geophys. Res. 105(E4) 9457-9475.

Ping J, Heki K, Matsumoto K and Tamura Y 2003 A degree 180 spherical harmonic model for the lunar topography; Adv. Space Res. 31(11) 2377-2382.

Potts L V and von Frese R R B 2003a Crustal attributes of lunar basins from terrain-correlated freeair gravity anomalies; J. Geophys. Res. 108(E5) 5037, doi:10.1029/2000JE001446.

Potts L V and von Frese R R B 2003b Comprehensive mass modeling of the Moon from spectrally correlated free-air and terrain gravity data; J. Geophys. Res. 108(E4) 5024, doi:10.1029/2000JE001440.

Rajmon D and Spudis P 2004 Distribution and stratigraphy of basaltic units in Maria Tranquillitatis and
Fecunditatis: A Clementine perspective; Meteorit. Planet. Sci. 39(10) 1699-1720.

Robinson M S and Jolliff B L 2002 Apollo 17 landing site: Topography, photometric corrections, and heterogeneity of the surrounding highland massifs; J. Geophys. Res. 107(E11) 5110, doi:10.1029/2001JE001614.

Robinson M S, Malaret E and White T 2003 A radiometric calibration for the Clementine HIRES camera; J. Geophys. Res. 108(E4) 5028, doi:10.1029/2000JE001241.

Robinson M S, Eliason E M, Hiesinger H, Jolliff B L, McEwen A S, Malin M C, Ravine M A, Roberts D, Thomas P C and Turtle E P 2005 LROC - Lunar Reconnaissance Orbiter Camera; Lunar and Planetary Science Conference XXXVI, Houston, TX, USA \#1576.

Shkuratov Y G, Kreslavsky M A, Ovcharenko A A, Stankevich D G, Zubko E S, Pieters C and Arnold G 1999 Opposition effect from Clementine data and mechanisms of backscatter; Icarus 141(1) 132-155.

Shkuratov Y G, Kaidash V G, Kreslavsky M A and Opanasenko N V 2001 Absolute calibration of the Clementine UVVIS data: Comparison with ground-based observation of the Moon; Solar Sys. Res. 35(1) 29-34.

Shkuratov Y G, Stankevich D G, Kaydash V G, Omelchenko V V, Pieters C M, Pinet P C, Chevrel S D, Daydou Y H, Foing B H, Sodnik Z, Josset J L, Taylor L A and Shevchenko V V 2003 Composition of the lunar surface as will be seen from SMART-1: A simulation using Clementine data; J. Geophys. Res. 108(E4) 5020, doi:10.1029/2002JE001971.

Shoemaker E M, Robinson M S and Eliason E M 1994 South-Pole region of the Moon as seen by Clementine; Science 266(5192) 1851-1854.

Simpson R A and Tyler G L 1999 Reanalysis of Clementine bistatic radar data from the lunar South Pole; J. Geophys. Res. 104(E2) 3845-3862.

Smith D E, Zuber M T, Neumann G A and Lemoine F G 1997 Topography of the Moon from the Clementine lidar; J. Geophys. Res. 102(E1) 1591-1611.

Spudis P D, Reisse R A and Gillis J J 1994 Ancient multiring basins on the Moon revealed by Clementine laser altimetry; Science 266(5192) 1848-1851.

Staid M I, Pieters C M and Head J W 1996 Mare Tranquillitatis: Basalt emplacement history and relation to lunar samples; J. Geophys. Res. 101(E10) 23,213-23,228.

Staid M I and Pieters C M 2000 Integrated spectral analysis of mare soils and craters: Applications to eastern nearside basalts; Icarus 145(1) 122-139.

Staid M I and Pieters C M 2001 Mineralogy of the last lunar basalts: Results from Clementine; J. Geophys. Res. 106(E11) 27,887-27,900.

Tompkins S and Pieters C M 1999 Mineralogy of the lunar crust: Results from Clementine; Meteorit. Planet. Sci. 34(1) 25-41.

von Frese R R B, Tan L, Potts L V, Kim J W, Merry C J and Bossler J D 1997 Lunar crustal analysis of Mare Orientale from topographic and gravity correlations; J. Geophys. Res. 102(E11) 25,657-25,675.

Warell J and Blewett D T 2004 Properties of the Hermean regolith: V. New optical reflectance spectra, comparison with lunar anorthosites, and mineralogical modelling; Icarus 168(2) 257-276.

Watters T R and Konopliv A S 2001 The topography and gravity of Mare Serenitatis: implications for subsidence of the mare surface; Planet. Space. Sci. 49(7) 743-748.

Weitz C M, Head J W and Pieters C M 1998 Lunar regional dark mantle deposits: Geologic, multispectral, and modeling studies; J. Geophys. Res. 103(E10) 22,725-22,759.

Weitz C M and Head J W 1999 Spectral properties of the Marius Hills volcanic complex and implications for the 
formation of lunar domes and cones; J. Geophys. Res. 104(E8) 18,933-18,956.

Wieczorek M A and Phillips R J 1997 The structure and compensation of the lunar highland crust; J. Geophys. Res. 102(E5) 10,933-10,943.

Wieczorek M A and Phillips R J 1998 Potential anomalies on a sphere: Applications to the thickness of the lunar crust; J. Geophys. Res. 103(E1) 1715-1724.

Wieczorek M A and Phillips R J 1999 Lunar multiring basins and the cratering process; Icarus 139(2) 246-259.

Wieczorek M A and Zuber M T 2001 The composition and origin of the lunar crust: Constraints from central peaks and crustal thickness modeling; Geophys. Res. Lett. 28(21) 4023-4026.

Wieczorek M A, Zuber M T and Phillips R J 2001 The role of magma buoyancy on the eruption of lunar basalts; Earth Planet. Sci. Lett. 185(1-2) 71-83.

Wilhelms D E 1987 The Geologic History of the Moon; Government Printing Office, Washington, D.C., pp. 302.

Williams K K and Zuber M T 1998 Measurement and analysis of lunar basin depths from Clementine altimetry; Icarus 131(1) 107-122.

Yingst R A and Head J W 1997 Volumes of lunar lava ponds in South Pole-Aitken and Orientale Basins:
Implications for eruption conditions, transport mechanisms, and magma source regions; J. Geophys. Res. 102(E5) 10,909-10,931.

Yingst R A and Head J W 1998 Characteristics of lunar mare deposits in Smythii and Marginis basins: Implications for magma transport mechanisms; J. Geophys. Res. 103(E5) 11,135-11,158.

Yingst R A and Head J W 1999 Geology of mare deposits in South Pole-Aitken basin as seen by Clementine UV/VIS data; J. Geophys. Res. 104(E8) 18,957-18,979.

Yokota Y, Iijima Y, Honda R, Okada T and Mizutani H 1999 Photometric properties of the moon: phase curves at small phase angles $\left(0-10^{\circ}\right)$ by Clementine images; $A d v$. Space Res. 23(11) 1841-1844.

Zellner N E B, Spudis P D, Delano J W and Whittet D C B 2002 Impact glasses from the Apollo 14 landing site and implications for regional geology; J. Geophys. Res. 107(E11) 5102, doi:10.1029/2001JE001800.

Zuber M T, Smith D E, Lemoine F G and Neumann G A 1994 The shape and internal structure of the Moon from the Clementine Mission; Science 266(5192) 1839-1843.

Zuber M T and Smith D E 1997 Topography of the lunar south polar region: Implications for the size and location of permanently shaded areas; Geophys. Res. Lett. 24(17) 2183-2186. 